\title{
Treatment of neurolept-induced tardive dyskinesia
}

This article was published in the following Dove Press journal:

Neuropsychiatric Disease and Treatment

12 September 2013

Number of times this article has been viewed

\section{Stacey K Jankelowitz}

Central Clinical School, University of Sydney, Sydney, NSW, Australia

Correspondence: Stacey K Jankelowitz Level 2, Medical Foundation Building, 92 Parramatta Road, Camperdown, Sydney, NSW, Australia

Tel +6/2 9036309 I

Fax +61290363092

Email stacey.jankelowitz@sydney.edu.au
Abstract: Tardive dyskinesia (TDK) includes orobuccolingual movements and "piano-playing" movements of the limbs. It is a movement disorder of delayed onset that can occur in the setting of neuroleptic treatment as well as in other diseases and following treatment with other drugs. The specific pathophysiology resulting in TDK is still not completely understood but possible mechanisms include postsynaptic dopamine receptor hypersensitivity, abnormalities of striatal gamma-aminobutyric acid (GABA) neurons, and degeneration of striatal cholinergic interneurons. More recently, the theory of synaptic plasticity has been proposed. Considering these proposed mechanisms of disease, therapeutic interventions have attempted to manipulate dopamine, GABA, acetylcholine, norepinephrine and serotonin pathways and receptors. The data for the effectiveness of each class of drugs and the side effects were considered in turn.

Keywords: tardive dyskinesia, treatment, neuroleptic agents

\section{Introduction}

Tardive dyskinesia (TDK) is a complex involuntary movement disorder that typically occurs in patients treated with antipsychotic drugs, but it usually has a delayed onset. The original description was published by Schonecker in $1957,{ }^{1}$ about five years after the commencement of neuroleptic treatment in psychiatry. Neuroleptic drugs are dopamine receptor blocking agents (DRBAs) and include metoclopramide, a dopamine antagonist used as an antiemetic, but which is also an antipsychotic at high doses and has a risk of TDK of $1 \%-10 \%{ }^{2,3}$ TDK refers to the orobuccolingual movements, as well as the "piano-playing" movements, of the fingers. Tardive syndrome (TS) includes a wider range of abnormal movements of delayed onset occurring in the setting of treatment with neuroleptic agents. TS includes tardive stereotypy, tardive dystonia, tardive tremor, tardive myoclonus, tardive parkinsonism, and tardive akathisia. TDK occurs in $20 \%-40 \%$ of neurolept-treated patients ${ }^{4-6}$ with an incidence of $5 \%$ per year. Jeste et $\mathrm{al}^{7}$ followed patients at $1-3$ month intervals and showed a cumulative incidence of TDK of $26 \%, 52 \%$, and $60 \%$ at 1, 2, and 3 years, respectively. The movements observed need to be distinguished from schizophrenia stereotypies and mannerisms, as well as other causes of orolingual movements, such as loose dentures. Movements similar to those seen in patients with TDK can also occur in other settings (Table 1), including Huntington's disease and Wilson's disease. These neurodegenerative conditions may manifest with psychiatric symptoms and/or abnormal movements. It is important to note that, in these syndromes, the movements are part of the syndrome and not a drug side effect. 
Table I Differential diagnosis of tardive dyskinesia

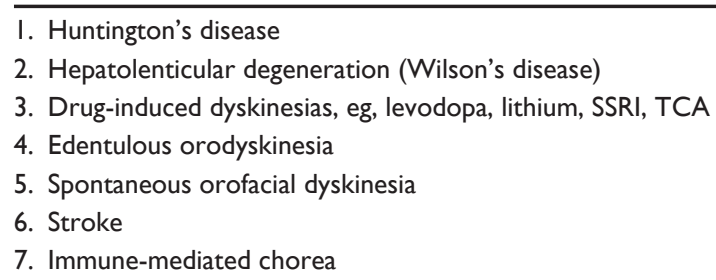

I. Huntington's disease

2. Hepatolenticular degeneration (Wilson's disease)

3. Drug-induced dyskinesias, eg, levodopa, lithium, SSRI, TCA

4. Edentulous orodyskinesia

5. Spontaneous orofacial dyskinesia

6. Stroke

7. Immune-mediated chorea

Abbreviations: SSRI, selective serotonin reuptake inhibitor; TCA, tricyclic antidepressants.

The pathophysiology of TDK and its predilection for orobuccolingual and upper limb muscles are still not fully understood. The basal ganglia and thalamus are the subcortical structures that make up the skeletomotor circuit (SMC). The ventral striatum is primarily involved in the emotional frontal-subcortical functions; ${ }^{8}$ whereas, the putamen mediates SMC function. ${ }^{9}$ The SMC is involved in control of voluntary movement, but it does not connect directly with the spinal cord. The SMC facilitates desired motor activity and inhibits activity that is undesirable or in competition with the desired activity. ${ }^{10}$ Prior to treatment with antipsychotics, activation from the motor cortex leads to increased activity in the select-on circuit in the SMC and to activation of the select-off pathway for competing motor behaviors. Dopaminergic input to the striatum enhances the select-on pathway through D1 receptors. D2 receptors (which function to inhibit) turn the control circuit on and limit competing behaviors. After antipsychotic treatment, D2 blockade results in loss of the control pathway with excess activity of the select-off (competing motor behaviors) circuit, but the D1 select-on function is unchanged. This altered circuitry may explain the acute akinetic effects of antipsychotics. Chronic antipsychotic treatment may result in D2 upregulation and sensitization with resultant excess activity in the control circuit, loss of the select-off circuit activity, and enhanced select-on activity through D1 unblocking, resulting in hyperkinesis and TDK. This focused selection model fits with the D2 upregulation hypothesis for TDK, but it ignores the GABA inhibition from the globus pallidus externa and the possibility of altered cholinergic transmission in TDK. This model, therefore, needs to be further refined to understand all the pathways involved in TDK. Further understanding of these pathways will also explain how deep brain stimulation is effective in treatment of TDK. ${ }^{11}$

Risk factors for TDK include female sex, older age, higher drug dose, long-term treatment, race, pre-existing mood, movement or cognitive disorder, alcohol use, diabetes, and human immunodeficiency virus (HIV) positivity
Table 2 Risk factors for tardive dyskinesia ${ }^{6,12-25}$
I. Age
2. Female sex
3. African-American race
4. Longer use and higher dose of neuroleptic agent
5. Preexisting mood disorder
6. Cognitive disturbance
7. Alcohol and substance abuse
8. Concomitant use of lithium and antiparkinsonian agents
9. Diabetes
10. HIV positivity
II. Typical neuroleptic agents
12. Early extrapyramidal symptoms

Abbreviation: HIV, human immunodeficiency virus.

(Table 2). ${ }^{6,12,13}$ However, unexpected effects of antipsychotics are well-reported with young, robust patients not tolerating small doses of drug, while older, feeble patients demonstrate no toxicity at high doses of antipsychotics. ${ }^{14}$ It has also been noted that siblings of patients with schizophrenia are more prone to TDK than controls, ${ }^{15}$ and spontaneous TDK can occur in treatment-naïve schizophrenic patients. ${ }^{16}$ This increased incidence of TDK in siblings of patients and the occurrence of spontaneous TDK in drug-naïve patients have raised the possibility of a genetic basis for the pathophysiology of TDK, which may reflect variations in genes associated with pharmacokinetic and pharmacodynamic processes of antipsychotic drugs or genetic profiles/polymorphisms that affect responsiveness to treatment. This genetic predisposition/variation may explain some of the heterogeneity of schizophrenia. With regard to genetic polymorphisms of enzymes metabolizing antipsychotic drugs, there have been some studies to show that a poor metabolizer phenotype of CYP2D6 has a greater risk of TDK. ${ }^{17-19}$ Studies of allelic association of CYP2D6 with TDK have, however, provided conflicting results. ${ }^{20-22}$ An association between TDK and a particular CYP1A2 genotype has been suggested ${ }^{23}$ but not confirmed ${ }^{24} \mathrm{~A}$ recent meta-analysis of CYP2D6 polymorphisms and risk of TDK suggests a minor effect of alleles with reduced function, but bias could not be excluded. ${ }^{25}$

The neurotransmitters implicated in the pathophysiology of TDK include postsynaptic dopamine receptor hypersensitivity, abnormalities of striatal GABA neurons, and degeneration of striatal cholinergic interneurons. ${ }^{6,26,27}$ Rosengarten et $\mathrm{al}^{28}$ proposed that TDK may be the result of an imbalance in dopaminergic receptor function. The dopamine receptor hypersensitivity theory proposes that chronic dopamine antagonism results in gradual hypersensitization of dopamine receptors..$^{29} \mathrm{D} 2$ receptor hypersensitivity has 
been demonstrated in rats, ${ }^{30,31}$ but direct evidence in humans is less strong; postmortem studies showing similar D2 receptor numbers between TDK and non-TDK patients. ${ }^{32}$ Biochemical isolation of different dopamine receptor subtypes and demonstration of subtype specific ligands ${ }^{33}$ has permitted further investigation of the dopamine pathophysiology of TDK. Malik et $\mathrm{al}^{34}$ studied the effects of D1, D2 and D3 agonists, and D3 antagonists on TDK in Cebus monkeys and demonstrated D3 agonists do indeed have an antidyskinetic effect. However, D3 agonists with D2 agonist effect as well, showed a greater improvement in dyskinesia than pure D3 agonists.

In Southeast Asian populations, there has been a suggestion of an association between certain D3 receptor polymorphisms and the development of TDK; however, this was not confirmed in a case control meta-analysis. ${ }^{35}$ Similarly, the association between serotonin receptor gene polymorphisms and TDK remains controversial. ${ }^{36-38}$ More recently, glutamatergic genes have also been implicated in the pathogenesis ofTDK. Further, in a genome-wide association screening, Syu et $\mathrm{al}^{39}$ have demonstrated that a single nucleotide polymorphism (SNP) in the heparin sulphate proteoglycan 2 gene (HSPG2) is associated with TDK in Japanese schizophrenic patients. This study was replicated in a Caucasian population, and a small association between an HSPG2 SNP and TDK was shown in an Ashkenazi Jewish cohort of schizophrenics. ${ }^{40}$ Genome-wide studies, however, are flawed by the number of calculations required and statistical corrections needed, as well as the stringent criteria for TDK used in some studies (see Müller et $\mathrm{al}^{41}$ for review). It has been suggested that the unifying theory for all the genes associated with TDK is that they all result in an abnormality of synaptic plasticity. Synaptic plasticity is modified by many factors, including the dopaminergic and GABAergic systems, ${ }^{42-44}$ and a recent study showed that schizophrenic patients with multiple psychotic episodes had impaired synaptic plasticity. ${ }^{45}$ This altered synaptic plasticity may explain the lack of improvement in TDK after withdrawal of antipsychotic medication, as well as the spontaneous dyskinesia in treatment-naïve schizophrenic patients and higher rate of dyskinesia in siblings. ${ }^{46}$

The onset of TDK is typically insidious; beginning several years after the initiation of treatment. The Diagnostic and Statistical Manual of Mental Disorders criteria specifies that the shortest duration of exposure to DRBAs is at least 1 month in patients 60 years or older. TDK reaches its maximum severity fairly rapidly and, then, often stabilises. The most common course is a waxing and waning of mild-to- moderate symptoms over many years, and clinical worsening after a period of stabilization is unusual. Approximately $11 \%$ of patients improve, usually within $1-2$ years of discontinuation of treatment. ${ }^{6}$ In classic TDK, the movements are rarely disabling and usually do not bother the patient, but they are of concern to family members. If clinically significant, swallowing and speech may be affected and can result in weight loss.

In view of the proposed pathophysiology of TDK, therapeutic interventions have attempted to manipulate dopamine, GABA, acetylcholine, norepinephrine and serotonin, and the data for the effectiveness of each class of drugs will be considered in turn.

\section{Prevention}

As TDK is an iatrogenic disorder, the best means of (but not possible) treatment would be prevention. However, patients do require treatment with neuroleptic agents, and these drugs are often the best treatment for long-term psychiatric disorders. Patients (and families) should be advised of the risk of TDK prior to commencing the drug, and the smallest effective dose of the safest drug should be used. Close monitoring for features of TDK or TS should be continued and, if possible, the dose reduced when features are first noticed and/or consideration given to changing to a drug with a lower risk of TDK.

\section{Atypical neuroleptics}

Atypical neuroleptics were initially thought to be at lower risk of inducing TDK; however, three prospective studies do not support this notion. ${ }^{47-49}$ Based on the dopamine hypersensitivity hypothesis (ie, prolonged dopamine antagonist therapy leads to dopamine hypersensitivity), both typical and atypical neuroleptic agents should suppress TDK, but the benefit is usually only in the short term and is greater with more potent agents. ${ }^{50}$ Sakai et $\mathrm{al}^{51}$ also showed that haloperidol upregulated GABA(a) receptor expression in the substantia nigra; whereas, newer generation drugs did not, providing an alternative reason for lower rates of TDK with newer drugs. There is little data to support the notion that atypical neuroleptics reduce TDK. There are case reports that quetiapine $^{52}$ and olanzapine ${ }^{53}$ can reduce TDK, but risperidone is the only atypical neuroleptic drug for which reasonable data is available. A single double-blind trial showed benefit with risperidone over haloperidol and placebo. Risperidone treatment resulted in a greater reduction in orobuccolingual movements compared to limb movements. ${ }^{54}$ However, at high doses of risperidone, there is a substantial risk of TDK. ${ }^{55}$ 
Clozapine, a relatively weak dopamine 2 receptor blocker, has also been shown to reduce abnormal movements in several small studies. ${ }^{56-59}$ Aripiprazole was developed to avoid TDK and is a partial D2 receptor agonist, the rationale being that lack of D2 blocking would lessen the amount of D2 hypersensitivity. ${ }^{60-63}$ However, case series of aripiprazoletreated patients do not support this theory. ${ }^{64,65}$

Despite the lack of substantial evidence, some experts suggest switching to an atypical neuroleptic to treat TDK and the psychiatric disturbance but do not distinguish between the various drugs. ${ }^{66}$ Atypical agents, however, have other side effects, including sedation, weight gain, diabetes, agranulocytosis, and psychiatric exacerbation. The risks and benefits should, therefore, be considered for each patient on an individual basis, given the varied results of existing studies.

\section{Dopamine depleting agents}

Tetrabenazine (TBZ; Xenazine ${ }^{\circledR}$ ) is a potent, selective, reversible depletor of monoamines from nerve terminals. TBZ inhibits the vesicular monoamine transporter type 2 which, in humans, is expressed nearly exclusively in the brain. TBZ is rapidly metabolized in the liver by carbonyl reductase to stereoisomers of hydrotetrabenazine, some of which are potent inhibitors of vesicular monoamine transporter type $2 .{ }^{67} \mathrm{TBZ}$ has been reported to be effective in treatment of TDK and tics, alleviating symptoms in up to $50 \%$ of patients. In more severe cases, there appears to be an additive effect, using a combination of tetrabenazine, clozapine, and clonazepam. ${ }^{68}$ In a recent systematic review, nine of eleven studies showed a benefit of tetrabenazine in the treatment of TDK. ${ }^{69}$ The largest prospective single-blinded study of TBZ included 20 patients with TDK present for 2-420 months and not responsive to other treatments. Seventeen out of 20 patients showed marked or moderate improvements as per the Abnormal Involuntary Movement Scale (AIMS). ${ }^{70}$ Reserpine is also an inhibitor of vesicular monoamine transport, thereby depleting stores of presynaptic dopamine. Tetrabenazine, however, has a quicker onset of action and fewer peripheral catecholamine-depleting effects, compared to reserpine. In favor of these drugs, neither has been shown to cause TDK, and while larger trials would be helpful, the available data support the use of tetrabenazine for suppression of TDK. ${ }^{67-69}$ It should, however, be noted that rapid increase in dose of tetrabenazine can cause other side effects, including marked rigidity/parkinsonism. ${ }^{67}$

\section{GABA agonists}

A systematic review of benzodiazepines in the treatment of TDK concluded that there is no clear evidence that benzodiazepines are effective in suppressing TDK, and use of benzodiazepines remains experimental. ${ }^{71}$ Nevertheless, there are studies of diazepam and clonazepam (GABA-A agonist) that show these drugs have some effect in reducing abnormal motor movements in patients with TDK, with $40 \%-50 \%$ of patients reporting some improvement. ${ }^{72,73}$ Thaker et $\mathrm{al}^{74}$ conducted a randomized controlled crossover study of 19 patients and showed a 35\% reduction in TDK with clonazepam; Bobruff et $\mathrm{al}^{75}$ also reported a significant reduction in TDK with clonazepam. There are conflicting reports on the efficacy of baclofen (a presynaptic GABA-B agonist) with it showing no effect alone, but having significant benefit when combined with neuroleptic agents. $^{76,77}$

Piracetam is a cyclic derivative of GABA. Its exact mechanism of action is uncertain. A randomized controlled trial of piracetam showed it to be effective in treatment of TDK. ${ }^{78}$ Abrupt cessation can, however, precipitate seizures.

Levetiracetam, structurally similar to piracetam, has also been shown to be effective in treatment of TDK in case reports, open-label studies, and in a randomized placebocontrolled trial. ${ }^{79}$ Gabapentin was shown to have a positive effect in an open-label trial, but there are no randomized controlled trials assessing the efficacy of gabapentin. ${ }^{80} \mathrm{~A}$ small, open-label trial suggests that zonisamide, a new antiepileptic for the treatment of partial seizures, is effective in treatment of TDK and well-tolerated. However, there is - once again no large randomized controlled trial to support this effect. ${ }^{81}$ Valproate, an epileptic with various mechanisms of action, was however found not to be effective in two studies. ${ }^{82,83}$

A recent Cochrane review (2011) concluded that "evidence of the effects of baclofen, progabide, sodium valproate, or tetrahydroisoxazolopyridine for people with antipsychotic-induced TDK is inconclusive and unconvincing. Any possible benefits are likely to be outweighed by the adverse cognitive effects associated with their use." 84

\section{Antioxidants}

Antioxidant drugs have been trialled in TDK after studies of the pathophysiology of the condition showed involvement of free radicals: chronic neuroleptic exposure increases dopamine turnover in the brain with subsequent production of cytotoxic-free radicals. A recent randomized controlled trial of ginkgo biloba versus placebo in Chinese schizophrenic patients demonstrated significant benefit in TDK as measured by the AIMS score. ${ }^{85}$ Vitamin E, which neutralizes free 
radicals, has been investigated in multiple studies. Although a large multicenter study showed minimal acute benefit on reducing abnormal motor movements, ${ }^{86-88}$ vitamin E may have more significant benefit at protecting against the deterioration of TDK symptoms over time. ${ }^{89}$ Melatonin, another antioxidant, was found to be effective in one randomized controlled trial..$^{90}$ Further, melatonin levels and the melatonin circadian rhythm are significantly low in schizophrenia, so treatment with melatonin may help remedy sleep disorders in schizophrenia, as well as aiding the antipsychotic treatment effect through its anti-inflammatory and antioxidative effect (see Anderson and Maes ${ }^{11}$ for review). Vitamin B6 was shown to be effective in two crossover studies, both done by the same group..$^{92}$

\section{Cholinergic versus anticholinergic agents}

It has been observed that parkinsonian features of TDK can be improved by dopamine agonists or cholinergic antagonists, suggesting an imbalance between acetylcholine and dopamine as a means of causing dyskinesias. Donepezil is the only drug that has consistently shown some benefit, ${ }^{93,94}$ despite the numerous studies of acetylcholinesterase inhibitors and cholinomimetic agents. A systematic review of cholinergic agents failed to show a clear-cut benefit for cholinergic agents in the treatment of TDK. However, in some studies, cholinergic agents were shown to be neither helpful nor detrimental. The authors of the systematic review suggested that researchers should not disregard this group of drugs (ie, cholinomimetics and acetylcholinesterase inhibitors), but larger trials of the best-tolerated drugs should be considered, especially in view of the absence of adverse effects with these drugs. ${ }^{95}$ Anticholinergics agents, however, are not only ineffective but appear to worsen TDK in some patients. ${ }^{96}$

\section{Dopaminergic agents}

Dopaminergic therapy has been studied to a limited extent. Naloxone, ${ }^{97,98}$ an opioid receptor agonist with dopaminemodulating effects, may have some benefit. Amantadine, which enhances presynaptic dopamine release, has been studied in two randomized controlled trials and has shown a significant reduction in TDK of up to $40 \%{ }^{99,100}$ Bromocriptine $^{101}$ and selegiline ${ }^{102}$ are considered to be ineffective. Buspirone, a serotonin receptor agonist that has some dopamine-modulating effects, is well-tolerated but is of variable benefit. ${ }^{103}$ From the recent research on the effect of different dopamine subtype agonists on TDK, ${ }^{34}$ it would be hoped that newer, more selective dopaminergic agents may be more effective in the management of TDK.

\section{Calcium channel blockers, beta blockers, etc}

Calcium channel blockers have been tried in the treatment of TDK. An analysis of five small randomized and eight nonrandomized studies could not refute nor support use of these drugs for TDK. ${ }^{104} \mathrm{~A}$ more recent systematic review of calcium channel blockers in the treatment of neurolepticinduced TDK concluded that there were no appropriate studies from which to draw conclusions. Their data search uncovered 15 possible studies, but eight were not randomized controlled trials, and the others were small or did not include patients with defined mental illnesses. The authors concluded that use of calcium channel blockers in the treatment of TDK is experimental, and large randomized controlled trials are needed to assess their effectiveness. ${ }^{105}$ Propranolol, a postsynaptic beta receptor blocker, has been reported to be effective in the management of TDK in several case reports and small open trials; but the evidence is weak, and abrupt cessation results in rebound of symptoms. ${ }^{106}$ Clonidine, a presynaptic alpha receptor agonist, has been shown to be effective in reducing TDK in a single randomized controlled trial. ${ }^{107}$

\section{Botulinum toxin}

As in other types of dystonia, botulinum toxin type A has been shown to be of benefit in treatment of tardive dystonia ${ }^{108}$ and is often injected into the tongue and masticatory muscles. ${ }^{109}$ In painful TDK, botulinum toxin is also reported to be of benefit. ${ }^{110}$

\section{Essential fatty acids}

As research studies reported high levels of phenylalanine in males with TDK, it was thought that branched chain amino acids may be effective in the treatment of TDK. A single double blind placebo-controlled trial showed a significant beneficial effect in patients with TDK. This effect is thought to be due to branched chain amino acids decreasing the concentrations of aromatic amino acids. Other essential fatty acids have also been studied but were shown to have no effect on TDK. ${ }^{111}$

\section{Surgery}

As medical treatments of TDK are often disappointing, recent studies of surgical interventions have been conducted. A few case reports have suggested some efficacy of lesioning surgery (ie, pallidotomy or thalamotomy). A much greater number of 
series (including one controlled study) have assessed the effects of deep brain stimulation applied to the globus interna. ${ }^{112-115}$ All of these studies have shown a marked improvement of motor symptoms without any major psychiatric side effects. A recent systematic review of deep brain stimulation (DBS) in TDK ${ }^{114}$ concludes that DBS greatly improves motor scores in patients with TDK (and tardive dystonia) and that psychiatric effects are limited, although this aspect was not always assessed. DBS would be considered appropriate treatment for patients who do not respond to or cannot tolerate pharmacological interventions. It is thought that the lack of psychiatric side effects may be that the globus pallidus interna (GPi) has been stimulated in TDK; whereas, in Parkinson's, the subthalamic nucleus is the target. Pallidal stimulation is also extremely effective for severe disabling tardive dystonia unresponsive to other forms of therapy. ${ }^{112-115}$

\section{Animal studies}

Ongoing research into the pathophysiology and treatment of TDK has involved predominantly a mouse model of TDK in which vacuous chewing movements are produced by exposure to neuroleptic drugs. Studies of this mouse model suggest that nicotine significantly reduces vacuous chewing movements induced by haloperidol. ${ }^{116}$ The exact mechanism of action of the nicotine is uncertain. However, this data needs to be treated with caution as a large review of Chinese schizophrenic patients reported that smoking was not protective against the development of TDK, nor did it increase the risk of developing TDK. ${ }^{117}$ In other mouse studies, fluphenazine induced vacuous chewing movements in $70 \%$ of animals, and the animals showed reduced locomotor and exploratory movements. Combining resveratrol (a polyphenol found in grapes and red wine) with fluphenazine reduced the prevalence, but not intensity, of the vacuous chewing movements down to $30 \%$ and also lessened the locomotor and exploratory effects of fluphenazine. These findings suggest that resveratrol may be neuroprotective in the presence of fluphenazine treatment. ${ }^{118}$

Deep brain stimulation has also recently been trialled for treatment resistant drug-induced TDK. In the rat model of vacuous chewing movements, deep brain stimulation has been performed at the entopeduncular nucleus (EPN) and subthalamic nucleus (STN). Stimulation at both sites is effective, and only unilateral stimulation is required. The stimulation parameters, however, vary with higher rates of stimulation more effective at the STN; whereas, at the EPN, low and high rates of stimulation were equally effective. ${ }^{119}$

Considering the complex motor pathways now described in the possible pathophysiology of TDK ${ }^{10,11}$ - as well as the
Table 3 Hierarchy of strategies in the management of tardive dyskinesia

I. Slowly reduce neuroleptic dose

2. Add or change to clozapine, quetiapine, or risperidone

3. Add tetrabenazine, reserpine, or vitamin $E$

4. Deep brain stimulation

evidence of altered synaptic plasticity in brain stimulation studies $^{46,114}$ - perhaps it would be more useful for further animal studies to be done on nonhuman primates whose motor control systems mirror more closely those of the human.

\section{TDK in adolescents and children}

The risk of TDK is lower with second-generation antipsychotics than first-generation drugs in children, but most of the use of these drugs has been off-label. ${ }^{120}$ In randomized controlled trials, Haas et al ${ }^{121,122}$ showed a higher risk of TDK in risperidone-treated children, and the risk of TDK was dose-related. Correll and Kane ${ }^{123}$ evaluated the risk for TDK after 1 year of atypical antipsychotic exposure in a meta-analysis of ten long-term studies including youths with minimal previous exposure to typical antipsychotics (783 with risperidone, 27 with quetiapine, and 19 with olanzapine). Only three new cases of TDK occurred during up to 3 years of treatment; in two of them, the symptomatology resolved after drug discontinuation. Although it can occur in the first phases of the treatment, the risk of TDK increases with longer treatments. A pilot study ${ }^{124}$ and the Treatment of Early Onset Schizophrenia Spectrum Disorders (TEOSS) ${ }^{125}$ have shown a relatively equal risk of TDK with olanzapine, risperidone, and aripiprazole. Findling et $\mathrm{al}^{126}$ showed an increased risk of TDK when treating schizophrenic children with aripiprazole compared to placebo. There are only open-label studies of quetiapine, ${ }^{127,128}$ and these do not report an increased risk of TDK in children. However, all these studies have been fairly small. Larger randomized controlled trials in schizophrenic patients are needed to document the true risk of TDK with these new drugs, to determine the drug with the lowest risk of TDK, and to determine the response of TDK to treatment. For now, the mainstay of treatment suggested is levodopa or amantadine, and switching patients to clozapine may be helpful. ${ }^{129}$

\section{Conclusion}

The treatment of TDK remains unsatisfactory, and the benefits of various agents need to be weighed against their side effects. However, given the advances in the pathophysiology of TDK, further therapeutic studies based on these findings 
may be helpful in optimizing the management of TDK. Clinicians need also to remember the added risk of TDK when combining the use of neuroleptics with metoclopramide in the same patient. ${ }^{2}$ Further, children appear to be at greater risk of extrapyramidal side effects, ${ }^{130,131}$ and the use of second-generation antipsychotics is increasing in children. ${ }^{132}$ Unfortunately, the most effective drugs for the treatment of TDK may have side effects that preclude their use long-term; whereas, less-effective drugs may have a more tolerable side effect profile (Table 3). Management is generally complex and needs to be individualized. As TDK is an iatrogenic disorder, it is best to limit the occurrence by prudent use of neuroleptic agents. Measures to limit the risk of TDK include: (1) critical, objective indications for neuroleptic drug use; (2) long-term use only for compelling or research-supported indications, primarily chronic psychotic illness that worsens when neuroleptic treatment is slowly discontinued; (3) using alternative treatments when neuroleptic treatment is elective, or early dyskinesia is identified; (4) using low but effective doses of single drugs, especially in the elderly; and (5) regular and specific examination for early detection of TDK. Once TDK becomes evident, it is prudent to use the lowest dose of drug necessary and avoiding other dopamine-blocking drugs. For severe dyskinesia, tetrabenazine is the most effective on the trial data available but does have side effects.

Benzodiazepines may be useful in less-prominent movements, and botulinum toxin is specifically useful in the presence of pain or dystonia. Deep brain stimulation remains an option in those patients with severe disabling TDK in whom several pharmacological agents, given an adequate duration of treatment, have not been effective.

\section{Disclosure}

The author reports no conflict of interest in this work.

\section{References}

1. Schonecker M. Paroxysmal dyskinesia as the effect of megaphen. Nervenarzt. 1957;28(12):550-553. German.

2. Kenney C, Hunter C, Davidson A, Jankovic J. Metoclopramide, an increasingly recognized cause of tardive dyskinesia. J Clin Pharmacol. 2008;48(3):379-384.

3. Rao AS, Camilleri M. Review article: metoclopramide and tardive dyskinesia. Aliment Pharmacol Ther. 2010;31(1):11-19.

4. Woerner MG, Kane JM, Lieberman J, et al. The prevalence of tardive dyskinesia. J Clin Psychopharmacol. 1991;11(1):34-42.

5. Kane JM, Smith JM. Tardive dyskinesia: prevalence and risk factors, 1959 to 1979. Arch Gen Psychiatry. 1982;39(4):473-481.

6. Eberhard J, Lindström E, Levander S. Tardive dyskinesia and antipsychotics: a 5-year longitudinal study of frequency, correlates and course. Int Clin Psychopharmacol. 2006;21(1):35-42.

7. Jeste DV, Caligiuri MP, Paulsen JS, et al. Risk of tardive dyskinesia in older patients. A prospective longitudinal study of 266 outpatients. Arch Gen Psychiatry. 1995;52(9):756-765.
8. Heimer L. A new anatomical framework for neuropsychiatric disorders and drug abuse. Am J Psychiatry. 2003;160(10):1726-1739.

9. Cummings JL. Frontal-subcortical circuits and human behavior. Arch Neurol. 1993;50(8):873-880.

10. Mink JW. The basal ganglia: focused selection and inhibition of competing motor programs. Prog Neurobiol. 1996;50(4):381-425.

11. Marchand WR, Dilda V. New models of frontal-subcortical skeletomotor circuit pathology in tardive dyskinesia. Neuroscientist. 2006;12(3):186-198.

12. Margolese HC, Chouinard G, Kolivakis TT, Beauclair L, Miller R, Annable L. Tardive dyskinesia in the era of typical and atypical antipsychotics. Part 2: Incidence and management strategies in patients with schizophrenia. Can J Psychiatry. 2005;50(11):703-714.

13. Shedlack KJ, Soldat-Couture C, Swanson CL Jr. Rapidly progressive tardive dyskinesia in AIDS. Biol Psychiatry. 1994;35(2):147-148.

14. Ohmori O, Shinkai T, Hori H, Matsumoto C, Nakamura J. A perspective on molecular genetic studies of tardive dyskinesia: one clue for individualized antipsychotic drug therapy. Prog Neuropsychopharmacol Biol Psychiatry. 2003;27(4):581-586.

15. Van Harten PN, Tenback DE. Tardive dyskinesia: clinical presentation and treatment. Int Rev Neurobiol. 2011;98:187-210.

16. Khot V, Wyatt RJ. Not all that moves is tardive dyskinesia. Am J Psychiatry. 1991;148(5):661-666.

17. Arthur H, Dahl ML, Siwers B, Sjöqvist F. Polymorphic drug metabolism in schizophrenic patients with tardive dyskinesia. $J$ Clin Psychopharmacol. 1995;15(3):211-216.

18. Andreassen OA, MacEwan T, Gulbrandsen AK, McCreadie RG, Steen VM. Non-functional CYP2D6 alleles and risk for neuroleptic-induced movement disorders in schizophrenic patients. Psychopharmacology (Berl). 1997;131(2):174-179.

19. Armstrong M, Daly AK, Blennerhassett R, Ferrier N, Idle JR. Antipsychotic drug-induced movement disorders in schizophrenics in relation to CYP2D6 genotype. Br J Psychiatry. 1997;170: 23-26.

20. Sachse C, Brockmöller J, Bauer S, Roots I. Cytochrome P450 2D6 variants in a Caucasian population: allele frequencies and phenotypic consequences. Am J Hum Genet. 1997;60(2):284-295.

21. Ohmori O, Kojimo H, Shinkai T, Terao T, Suzuki T, Abe K. Genetic association analysis between CYP2D6*2 allele and tardive dyskinesia in schizophrenic patients. Psychiatry Res. 1999;87(2-3):239-244.

22. Lam LC, Garcia-Barcelo MM, Ungvari GS, et al. Cytochrome P450 2D6 genotyping and association with tardive dyskinesia in Chinese schizophrenic patients. Pharmopsychiatry. 2001;34(6):238-241.

23. Basile VS, Ozdemir V, Masellis M, et al. A functional polymorphism of the cytochrome P450 1A2 (CYP1A2) gene: association with tardive dyskinesia in schizophrenia. Mol Psychiatry. 2000;5(4):410-417.

24. Schulze TG, Schumacher J, Müller D, et al. Lack of association between a functional polymorphism of the cytochrome P450 1A2 (CYP1A2) gene and tardive dyskinesia in schizophrenia. Am J Med Genet. 2001;105(6): 498-501.

25. Patsopoulos NA, Ntzani EE, Zintzaras E, Ioannidis JP. CYP2D6 polymorphisms and the risk of tardive dyskinesia in schizophrenia: a meta-analysis. Pharmacogenet Genomics. 2005;15(3):151-158.

26. Miller R, Chouinard G. Loss of striatal cholinergic neurons as a basis for tardive and L-dopa-induced dyskinesias, neuroleptic-induced supersensitivity psychosis and refractory schizophrenia. Biol Psychiatry. 1993;34(10):713-738.

27. Sachdev PS. The current status of tardive dyskinesia. Aust $N Z J$ Psychiatry. 2000;34(3):355-369.

28. Rosengarten H, Schweitzer JW, Friedhoff AJ. Induction of oral dyskinesias in naive rats by D1stimulation. Life Sci. 1983;33(25): 2479-2482.

29. Marsden CD, Jenner P. The pathophysiology of extrapyramidal sideeffects of neuroleptic drugs. Psychol Med. 1980;10(1):55-72.

30. Calabresi P, De Murtas M, Mercuri NB, Bernardi G. Chronic neuroleptic treatment: D2 dopamine receptor supersensitivity and striatal glutamatergic transmission. Ann Neurol. 1992;31(4):366-373. 
31. Turrone P, Remington G, Kapur S, Nobrega JN. The relationship between dopamine D2 receptor occupancy and the vacuous chewing movement syndrome in rats. Psychopharmacology (Berl). 2003;165(2): $166-171$.

32. Crow TJ, Cross AJ, Johnstone EC, Owen F, Owens DG, Waddington JL. Abnormal involuntary movements in schizophrenia: are they related to the disease process or its treatment? Are they associated with changes in dopamine receptors? J Clin Psychopharmacol. 1982;2(5):336-340.

33. Sibley DR, Monsma FJ Jr, Shen Y. Molecular biology of dopaminergic receptors. Int Rev Neurobiol. 1993;35:391-415.

34. Malik P, Andersen MB, Peacock L. The effects of dopamine D3 agonists and antagonists in a nonhuman primate model of tardive dyskinesia. Pharmacol Biochem Behav. 2004;78(4):805-810.

35. Utsunomiya K, Shinkai T, Sakata S, et al. Genetic association between the dopamine D3 receptor gene polymorphism (Ser9Gly) and tardive dyskinesia in patients with schizophrenia: a reevaluation in East Asian populations. Neurosci Lett. 2012;507(1):52-56.

36. Basile VS, Ozdemir V, Masellis M, et al. Lack of association between serotonin-2A receptor gene (HTR2A) polymorphisms and tardive dyskinesia in schizophrenia. Mol Psychiatry. 2001;6(2):230-234.

37. Segman RH, Heresco-Levy U, Finkel B, et al. Association between the serotonin $2 \mathrm{~A}$ receptor gene and tardive dyskinesia in chronic schizophrenia. Mol Psychiatry. 2001;6(2):225-229.

38. Ohmori O, Shinkai T, Hori H, Nakamura J. Genetic association analysis of 5-HT(6) receptor gene polymorphism (267C/T) with tardive dyskinesia. Psychiatry Res. 2002;110(2):97-102.

39. Syu A, Ishiguro H, Inada T, et al. Association of the HSPG2 gene with neuroleptic-induced tardive dyskinesia. Neuropsychopharmacology. 2010;35(5):1155-1164.

40. Greenbaum L, Alkelai A, Zozulinsky P, Kohn Y, Lerer B. Support for association of HSPG2 with tardive dyskinesia in Caucasian populations. Pharmacogenomics J. 2012;12(6):513-520.

41. Müller DJ, Chowdhury NI, Zai CC. The pharmacogenetics of antipsychotic-induced adverse events. Curr Opin Psychiatry. 2013; 26(2):144-150.

42. Nitsche MA, Müller-Dahlhaus F, Paulus W, Ziemann U. The pharmacology of neuroplasticity induced by non-invasive brain stimulation: building models for the clinical use of CNS active drugs. $J$ Physiol. 2012;590(Pt 19):4641-4662.

43. Teo JT, Terranova C, Swayne O, Greenwood RJ, Rothwell JC. Differing effects of intracortical circuits on plasticity. Exp Brain Res. 2009;193(4):555-563.

44. Korchounov A, Ziemann U. Neuromodulatory neurotransmitters influence LTP-like plasticity in human cortex: a pharmaco-TMS study. Neuropsychopharmacology. 2011;36(9):1894-1902.

45. Hasan A, Misewitsch K, Nitsche MA, et al. Impaired motor cortex responses in non-psychotic first-degree relatives of schizophrenia patients: a cathodal tDCS pilot study. Brain Stimul. Epub March 22, 2013.

46. Teo JT, Edwards MJ, Bhatia K. Tardive dyskinesia is caused by maladaptive synaptic plasticity: a hypothesis. Mov Disord. 2012;27(10): 1205-1215.

47. Woods SW, Morgenstern H, Saksa JR, et al. Incidence of tardive dyskinesia with atypical versus conventional antipsychotic medications: a prospective cohort study. J Clin Psychiatry. 2010;71(4):463-474.

48. Kahn RS, Fleischhacker WW, Boter H, et al; EUFEST study group. Effectiveness of antipsychotic drugs in first-episode schizophrenia and schizophreniform disorder: an open randomised clinical trial. Lancet. 2008;371(9618):1085-1097.

49. Leucht S, Kissling W, Davis JM. Second-generation antipsychotics for schizophrenia: can we resolve the conflict? Psychol Med. 2009;39(10): 1591-1602.

50. Egan MF, Apud J, Wyatt RJ. Treatment of tardive dyskinesia. Schizophr Bull. 1997;23(4):583-609.

51. Sakai K, Gao XM, Hashimoto T, Tamminga CA. Traditional and new antipsychotic drugs differentially alter neurotransmission markers in basal ganglia-thalamocortical neural pathways. Synapse. 2001;39(2): $152-160$.
52. Vesely C, Küfferle B, Brücke T, Kasper S. Remission of severe tardive dyskinesia in a schizophrenic patient treated with the atypical antipsychotic substance quetiapine. Int Clin Psychopharmacol. 2000;15(1): $57-60$.

53. Soutullo CA, Keck PE Jr, McElroy SL. Olanzapine in the treatment of tardive dyskinesia: a report of two cases. J Clin Psychopharmacol. 1999;19(1):100-101.

54. Chouinard G. Effects of risperidone in tardive dyskinesia: an analysis of the Canadian multicenter risperidone study. J Clin Psychopharmacol. 1995;15(1 Suppl 1):36S-44S.

55. Tarsy D, Lungu C, Baldessarini RJ. Epidemiology of tardive dyskinesia before and during the era of modern antipsychotic drugs. Handb Clin Neurol. 2011;100:601-616.

56. Factor SA, Friedman JH. The emerging role of clozapine in the treatment of movement disorders. Mov Disord. 1997;12(4):483-496.

57. Simpson GM, Lee JH, Shrivastava RK. Clozapine in tardive dyskinesia. Psychopharmacol (Berl). 1978;56(1):75-80.

58. Lieberman JA, Saltz BL, Johns CA, Pollack S, Borenstein M, Kane J. The effects of clozapine on tardive dyskinesia. Br J Psychiatry. 1991;158:503-510.

59. Small JG, Milstein V, Marhenke JD, Hall DD, Kellams JJ. Treatment outcome with clozapine in tardive dyskinesia, neuroleptic sensitivity, and treatment-resistant psychosis. J Clin Psychiatry. 1987;48(7): 263-267.

60. Natesan S, Reckless GE, Nobrega JN, Fletcher PJ, Kapur S. Dissociation between in vivo occupancy and functional antagonism of dopamine D2 receptors: comparing aripiprazole to other antipsychotics in animal models. Neuropsychopharmacology. 2006;31(9):1854-1863.

61. Shapiro DA, Renock S, Arrington E, et al. Aripiprazole, a novel atypical antipsychotic drug with a unique and robust pharmacology. Neuropsychopharmacology. 2003;28(8):1400-1411.

62. Tamminga CA, Carlsson A. Partial dopamine agonists and dopaminergic stabilisers, in the treatment of psychosis. Curr Drug Targets CNS Neurol Disord. 2002;1(2):141-147.

63. Evcimen YA, Evcimen H, Holland J. Aripiprazole-induced tardive dyskinesia: the role of tamoxifen. Am J Psychiatry. 2007;164(9): 1436-1437.

64. Peña MS, Yaltho TC, Jankovic J. Tardive dyskinesia and other movement disorders secondary to aripiprazole. Mov Disord. 2011;26(1): 147-152.

65. Schwartz T, Raza S. Aripiprazole (abilify) and tardive dyskinesia. $P$ T. 2008;33(1):32-34.

66. Simpson GM. The treatment of tardive dyskinesia and tardive dystonia. J Clin Psychiatry. 2000;61(Suppl 4):39-44.

67. Jankovic J, Clarence-Smith K. Tetrabenazine for the treatment of chorea and other hyperkinetic movement disorders. Expert Rev Neurother. 2011;11(11):1509-1523.

68. Kimiagar I, Dobronevsky E, Prokhorov T, Miniovitz A, Rabey JM. Rapid improvement of tardive dyskinesia with tetrabenazine, clonazepam and clozapine combined: a naturalistic long-term follow-up study. J Neurol. 2012;259(4):660-664.

69. Chen JJ, Ondo WG, Dashtipour K, Swope DM. Tetrabenazine for the treatment of hyperkinetic movement disorders: a review of the literature. Clin Ther. 2012;34(7):1487-1504.

70. Ondo WG, Hanna PA, Jankovic J. Tetrabenazine treatment for tardive dyskinesia: assessment by randomized videotape protocol. Am J Psychiatry. 1999;156(8):1279-1281.

71. Soares KV, McGrath JJ, Deeks JJ. Gamma-aminobutyric acid agonists for neuroleptic-induced tardive dyskinesia [review]. Cochrane Database Syst Rev. 2001;2:CD000203.

72. Thaker GK, Nguyen JA, Strauss ME, Jacobson R, Kaup BA, Tamminga CA. Clonazepam treatment of tardive dyskinesia: a practical GABAmimetic strategy. Am J Psychiatry. 1990;147(4):445-451.

73. Singh MM, Becker RE, Pitman RK, Nasrallah HA, Lal H. Sustained improvement in tardive dyskinesia with diazepam: indirect evidence for corticolimbic involvement. Brain Res Bull. 1983;11(2): 179-185. 
74. Thaker GK, Tamminga CA, Alphs LD, Lafferman J, Ferraro TN, Hare TA. Brain gamma-aminobutyric acid abnormality in tardive dyskinesia. Reduction in cerebrospinal fluid GABA levels and therapeutic response to GABA agonist treatment. Arch Gen Psychiatry. 1987;44(6):522-529.

75. Bobruff A, Gardos G, Tarsy D, Rapkin RM, Cole JO, Moore P. Clonazepam and phenobarbital in tardive dyskinesia. Am J Psychiatry. 1981;138(2):189-193.

76. Stewart RM, Rollins J, Beckham B, Roffman M. Baclofen in tardive dyskinesia patients maintained on neuroleptics. Clin Neuropharmacol. 1982;5(4):365-373.

77. Gerlach J, Rye T, Kristjansen P. Effect of baclofen on tardive dyskinesia. Psychopharmacol (Berl). 1978;56(2):145-151.

78. Libov I, Miodownik C, Bersudsky Y, Dwolatzky T, Lerner V. Efficacy of piracetam in the treatment of tardive dyskinesia in schizophrenic patients: a randomized, double-blind, placebo-controlled crossover study. J Clin Psychiatry. 2007;68(7):1031-1037.

79. Woods SW, Saksa JR, Baker CB, Cohen SJ, Tek C. Effects of levetiracetam on tardive dyskinesia: a randomized, double-blind, placebocontrolled study. J Clin Psychiatry. 2008;69(4):546-554.

80. Hardoy MC, Carta MG, Carpiniello B, et al. Gabapentin in antipsychotic-induced tardive dyskinesia: results of 1-year follow-up. J Affect Disord. 2003;75(2):125-130.

81. Iwata $\mathrm{Y}$, Irie $\mathrm{S}$, Uchida $\mathrm{H}$, et al. Effects of zonisamide on tardive dyskinesia: a preliminary open-label trial. J Neurol Sci. 2012;315(1-2): 137-140.

82. Fisk GG, York SM. The effect of sodium valproate on tardive dyskinesia - revisited. Br J Psychiatry. 1987;150:542-546.

83. Nasrallah HA, Dunner FJ, McCalley-Whitters M. A placebo-controlled trial of valproate in tardive dyskinesia. Biol Psychiatry. 1985;20(2): 205-208.

84. Alabed S, Latifeh Y, Mohammad HA, Rifai A. Gamma-aminobutyric acid agonists for neuroleptic-induced tardive dyskinesia [review]. Cochrane Database Syst Rev. 2011;4:CD000203.

85. Zhang WF, Tan YL, Zhang XY, Chan RC, Wu HR, Zhou DF. Extract of Ginkgo biloba treatment for tardive dyskinesia in schizophrenia: a randomized, double-blind, placebo-controlled trial. J Clin Psychiatry. 2011;72(5):615-621.

86. Egan MF, Hyde TM, Albers GW, et al. Treatment of tardive dyskinesia with vitamin E. Am J Psychiatry. 1992;149(6):773-777.

87. Adler LA, Peselow E, Rotrosen J, et al. Vitamin E treatment of tardive dyskinesia. Am J Psychiatry. 1993;150(9):1405-1407.

88. Adler LA, Rotrosen J, Edson R, et al. Vitamin E treatment for tardive dysklinesia. Veterans Affairs Cooperative Study \#394 Study Group Arch Gen Psychiatry. 1999;56(9):836-841.

89. Soares-Weiser K, Maayan N, McGrath J. Vitamin E for neurolepticinduced tardive dyskinesia [review]. Cochrane Database Syst Rev. 2011;2:CD000209.

90. Shamir E, Barak Y, Shalman I, et al. Melatonin treatment for tardive dyskinesia: a double-blind, placebo-controlled, crossover study. Arch Gen Psychiatr. 2001;58(11):1049-1052.

91. Anderson G, Maes M. Melatonin: an overlooked factor in schizophrenia and in the inhibition of anti-psychotic side effects. Metab Brain Dis 2012;27(2):113-119.

92. Lerner V, Miodownik C, Kaptsan A, et al. Vitamin B6 treatment for tardive dyskinesia: a randomized, double-blind, placebo-controlled, crossover study. J Clin Psychiatry. 2007;68(11):1648-1654.

93. Bergman J, Dwolatzky T, Brettholz I, Lerner V. Beneficial effect of donepezil in the treatment of elderly people with tardive movement disorders. J Clin Psychiatry. 2005;66(1):107-110.

94. Caroff SN, Campbell EC, Havey JC, Sullivan KA, Katz IR, Mann SC. Treatment of tardive dyskinesia with donepezil. J Clin Psychiatry. 2001;62(2):128-129.

95. Tammenmaa IA, Sailas E, McGrath JJ, Soares-Weiser K, Wahlbeck K. Systematic review of cholinergic drugs for neuroleptic-induced tardive dyskinesia: a meta-analysis of randomized controlled trials. Prog Neuropsychopharmacol Biol Psychiatry. 2004;28(7):1099-1107.
96. Desmarais JE, Beauclair L, Margolese HC. Anticholinergics in the era of atypical antipsychotics: short-term or long-term treatment? J Psychopharmacol. 2012;26(9):1167-1174.

97. Blum I, Nisipeanu PF, Roberts E. Naloxone in tardive dyskinesia. Psychopharmacol (Berl). 1987;93(4):538.

98. Lindenmayer JP, Gardner E, Goldberg E, et al. High-dose naloxone in tardive dyskinesia. Psychiatry Res. 1988. 26(1):19-28.

99. Angus S, Sugars J, Boltezar R, Koskewich S, Schneider NM. A controlled trial of amantadine hydrochloride and neuroleptics in the treatment of tardive dyskinesia. J Clin Psychopharmacol. 1997;17(2):88-91.

100. Pappa S, Tsouli S, Apostolou G, Mavreas V, Konitsiotis S. Effects of amantadine on tardive dyskinesia: a randomized, double-blind, placebocontrolled study. Clin Neuropharmacol. 2010;33(6):271-275.

101. Lieberman JA, Alvir J, Mukherjee S, Kane JM. Treatment of tardive dyskinesia with bromocriptine. A test of the receptor modification strategy. Arch Gen Psychiatry. 1989;46(10):908-913.

102. Goff DC, Renshaw PF, Sarid-Segal O, Dreyfuss DA, Amico ET, Ciraulo DA. A placebo-controlled trial of selegiline (L-deprenyl) in the treatment of tardive dyskinesia. Biol Psychiatry. 1993;33(10): 700-706.

103. Moss LE, Neppe VM, Drevets WC. Buspirone in the treatment of tardive dyskinesia. J Clin Psychopharmacol. 1993;13(3):204-209.

104. Soares-Weiser KK, Rathbone J. Calcium channel blockers for neuroleptic-induced tardive dyskinesia [review]. Cochrane Database Syst Rev. 2004;1:CD000206.

105. Essali A, Deirawan H, Soares-Weiser K, Adams CE. Calcium channel blockers for neuroleptic-induced tardive dyskinesia [review] Cochrane Database Syst Rev. 2011;11:CD000206.

106. Aia PG, Revuelta GJ, Cloud LJ, Factor SA. Tardive dyskinesia. Curr Treat Options Neurol. 2011;13(3):231-241.

107. Browne J, Silver H, Martin R, Hart R, Mergener M, Williams P. The use of clonidine in the treatment of neuroleptic-induced tardive dyskinesia. J Clin Psychopharmacol. 1986;6(2):88-92.

108. Jankovic J, Brin MF. Therapeutic uses of botulinum toxin. $N$ Engl J Med. 1991;324(17):1186-1194.

109. Rapaport A, Sadeh M, Stein D, et al. Botulinum toxin for the treatment of oro-facial-lingual-masticatory tardive dyskinesia. Mov Disord. 2000;15(2):352-355

110. Tschopp L, Salazar Z, Micheli F. Botulinum toxin in painful tardive dyskinesia. Clin Neuropharmacol. 2009;32(3):165-166.

111. Emsley R, Niehaus DJ, Koen L, et al. The effects of eicosapentaenoic acid in tardive dyskinesia: a randomized, placebo-controlled trial. Schizophr Res. 2006;84(1):112-120.

112. Eltahawy HA, Feinstein A, Khan F, Saint-Cyr J, Lang AE, Lozano AM. Biltaeral globus pallidus internus deep brain stimulation in tardive dyskinesia: a case report. Mov Disord. 2004;19(8):969-972.

113. Damier P, Thobois S, Witjas T, et al; French Stimulation for Tardive Dyskinesia (STARDYS) Study Group. Bilateral deep brain stimulation of the globus pallidus to treat tardive dyskinesia. Arch Gen Psychiatry. 2007;64(2):170-176.

114. Mentzel CL, Tenback DE, Tijssen MA, Visser-Vandewalle VE, van Harten PN. Efficacy and safety of deep brain stimulation in patients with medication-induced tardive dyskinesia and/or dystonia: a systemic review. J Clin Psychiatry. 2012;73(11):1434-1438.

115. Kefalopoulou Z, Paschali A, Markaki E, Vassilakos P, Ellul J, Constantoyannis C. A double-blind study on a patient with tardive dyskinesia treated with pallidal deep brain stimulation. Acta Neurol Scand. 2009;119(4):269-273.

116. Bordia T, McIntosh JM, Quik M. Nicotine reduces antipsychoticinduced orofacial dyskinesia in rats. J Pharmacol Exp Ther. 2012; 340(3):612-619.

117. Zhang XY, Yu YQ, Sun S, et al. Smoking and tardive dyskinesia in male patients with chronic schizophrenia. Prog Neuropsychopharmacol Biol Psychiatry. 2011;35(7):1765-1769.

118. Busanello A, Peroza LR, Wagner C, et al. Resveratrol reduces vacuous chewing movements induced by acute treatment with fluphenazine. Pharmacol Biochem Behav. 2012;101(2):307-310. 
119. Creed M, Hamani C, Nobrega JN. Deep brain stimulation of the subthalamic or entopeduncular nucleus attenuates vacuous chewing movements in a rodent model of tardive dyskinesia. Eur Neuropsychopharmacol. 2011;21(5):393-400.

120. Pringsheim T, Doja A, Belanger S, Patten S; Canadian Alliance for Monitoring Effectiveness and Safety of Antipsychotics in Children (CAMESA) guideline group. Treatment recommendations for extrapyramidal side effects associated with second-generation antipsychotic use in children and youth. Paediatr Child Health. 2011;16(9):590-598.

121. Haas M, Eerdekens M, Kushner L, et al. Efficacy, safety and tolerability of two dosing regimens in adolescent schizophrenia: double-blind study. Br J Psychiatry. 2009;194(2):158-164.

122. Haas M, Unis AS, Armenteros J, Copenhaver MD, Quiroz JA, Kushner SF. A 6-week, randomized, double-blind placebo-controlled study of the efficacy and safety of risperidone in adolescent with schizophrenia. J Child Adolesc Psychopharmacol. 2009;19(6): 611-621.

123. Correll CU, Kane JM. One-year incidence rates of tardive dyskinesia in children and adolescents treated with second-generation antipsychotics: a systematic review. J Child Adolesc Psychopharmacol. 2007; 17(5):647-656.

124. Sikich L, Hamer RM, Bashford RA, Sheitman BB, Lieberman JA. A pilot study of risperidone, olanzapine, and haloperidol in psychotic youth: a double-blind, randomized, 8-week trial. Neuropsychopharmacology. 2004;29(1):133-145.
125. Sikich L, Frazier JA, McClellan J, et al. Double-blind comparison of first- and second-generation antipsychotics in early-onset schizophrenia and schizo-affective disorder: findings from the treatment of early-onset schizophrenia spectrum disorder (TEOSS) study. Am J Psychiatry. 2008;165(11):1420-1431.

126. Findling RL, Robb A, Nyilas M, et al. A multiple-center, randomized, double-blind, placebo-controlled study of oral aripiprazole for treatment of adolescents with schizophrenia. Am J Psychiatry. 2008;165(11):1432-1441.

127. McConville BJ, Arvanitis LA, Thyrum PT, et al. Pharmacokinetics, tolerability, and clinical effectiveness of quetiapine fumarate: an openlabel trial in adolescents with psychotic disorders. J Clin Psychiatry. 2000;61(4):252-260.

128. Schimmelmann BG, Mehler-Wex C, Lambert M, et al. A prospective 12-week study of quetiapine in adolescents with schizophrenia spectrum disorders. J Child Adolesc Psychopharmacol. 2007;17(6): 768-778.

129. Masi G, Liboni F. Management of schizophrenia in children and adolescents: focus on pharmacotherapy. Drugs. 2011;71(2): 179-208.

130. Correll CU. Safety and tolerability of antipsychotic treatment in young patients with schizophrenia. J Clin Psychiatry. 2011;72(8):e26.

131. Rasimas JJ, Liebelt EL. Adverse effects and toxicity of the atypical antipsychotics: what is important for the pediatric emergency medicine practitioner. Clin Pediatr Emerg Med. 2012;13(4):300-310.

132. Patten SB, Waheed W, Bresee L. A review of pharmacoepidemiologic studies of antipsychotic use in children and adolescents. Can J Psychiatry. 2012;57(12):717-721.
Neuropsychiatric Disease and Treatment

\section{Publish your work in this journal}

Neuropsychiatric Disease and Treatment is an international, peerreviewed journal of clinical therapeutics and pharmacology focusing on concise rapid reporting of clinical or pre-clinical studies on a range of neuropsychiatric and neurological disorders. This journal is indexed on PubMed Central, the 'PsycINFO' database and CAS.

\section{Dovepress}

The manuscript management system is completely online and includes a very quick and fair peer-review system, which is all easy to use. Visit http://www.dovepress.com/testimonials.php to read real quotes from published authors. 